\title{
EVN NRLDC XÂY DỰNG VĂN HÓA DOANH NGHIỆP (VHDN)
}

Trung tâm Điều độ Hệ thống điện miền Bắc

April 09, 2019

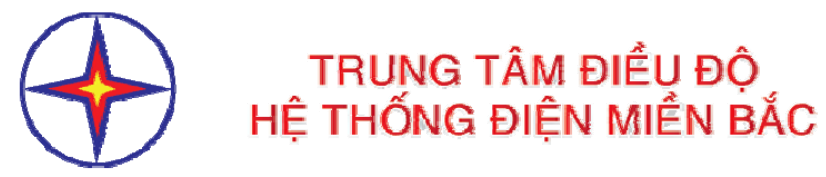

\section{EVNWRLDC}

https://www.nrldc.evn.vn/newsg/19/9919/XAY-DUNG-VAN-HOA-DOANHNGHIEP-VHDN-YEU-TO-QUYET-DINH-SU-TRUONG-TON-CUA-DOANHNGHIEP/default.aspx 


\section{XAY-DUNG-VAN-HOA-DOANH-NGHIEP- VHDN-YEU-TO-QUYET-DINH-SU-TRUONG- TON-CUA-DOANH-NGHIEP}

\section{XÂY DỰNG VĂN HÓA DOANH NGHIỆP (VHDN) - YẾU TỐ QUYẾT ĐỊNH SỤ TRƯỜNG TỔN CỦA DOANH NGHIỆP}

Trong một doanh nghiệp, đặc biệt là những doanh nghiệp có quy mô lớn, là một tập hợp những con người khác nhau về trình độ chuyên môn, trình độ văn hóa, mức độ nhận thức, quan hệ xã hội, vùng miền địa lý, tư tưởng văn hóa... chính sự khác nhau này tạo ra một môi trường làm việc đa dạng và phức tạp. Bên cạnh đó, với sự cạnh tranh gay gắt của nền kinh tế thị trường và xu hướng toàn cầu hóa, buộc các doanh nghiệp để tồn tại và phát triển phải liên tục tìm tòi những cái mới, sáng tạo và thay đổi cho phù hợp với thực tế. Vậy làm thế nào để doanh nghiệp trở thành nơi tập hợp, phát huy mọi nguồn lực con người, làm gia tăng nhiều lần giá trị của từng nguồn lực con người đơn lẻ, góp phần vào sự phát triển bền vững. Mặt khác xây dựng VHDN còn là một yêu cầu tất yếu của chính sách phát triển thương hiệu vì thông qua hình ảnh văn hóa doanh nghiệp sẽ góp phần quảng bá thương hiệu của doanh nghiệp. VHDN chính là tài sản vô hình của mồi doanh nghiệp.

\section{1. về VHDN Giới thiệu \\ 1. Khái niệm}

VHDN là những giá trị, niềm tin, hình thức mà mọi người trong doanh nghiệp cùng công nhận và suy nghĩ, nói, hành động như một thói quen, giống như đời sống tinh thần và tính cách của một con người, và là phần quyết định đến sự thành bại về lâu dài của doanh nghiệp.

Những thành phần của VHDN gồm 3 phần chính : tầm nhìn, sứ mệnh và giá trị cốt lõi. Biểu hiện của văn hóa doanh nghiệp thể hiện qua 2 yếu tố

- Hữu hình: Đồng phục, khẩu hiệu, nghi thức, quy định, nhạc phim công ty, tập san nội bộ, các hoạt động,...

- Vô hình: Thái độ, phong cách, thói quen, nếp nghĩ của những con người trong tổ chức.

Hiện nay có rất nhiều định nghĩa xoay quanh về khái niệm VHDN, có một vài cách định nghĩa khác như :

"Phẩm chất riêng biệt của tổ chức được nhận thức phân biệt nó vói các tổ chưc khác trong lĩnh vục”. (Gold, K.A.).

"Văn hóa thể hiện tổng hợp các giá trị và cách hành xủ phu thuộc lẫn nhau phổ biến trong doanh nghiệp và có xu hwớng tụ luu truyền, thwòng trong thòi gian dài”. (Kotter, J.P. \& Heskett, J.L.).

"Văn hóa doanh nghiệp là nhũng niềm tin, thái độ và giá trị tồn tại phổ biến và tuong đối ổn định trong doanh nghiệp”. (Williams, A., Dobson, P. \& Walters, M.).

Nhìn chung, mọi định nghĩa về văn hóa doanh nghiệp đều được giải thích thông qua giá trị chung của doanh nghiệp, thường là những giá trị vô hình 
được đúc kết qua nhiều năm và là cái quan trọng nhất của doanh nghiệp.

\section{Những giá trị đúc kết nên VHDN}

Tinh thần doanh nghiệp và quan điểm giá trị của doanh nghiệp là yếu tố hình thành nên văn hóa doanh nghiệp. Trong cuốn sách "Văn mình làm giàu và nguồn gốc của cải của" TS. Vương Quân Hoàng, chúng ta đã được đề cập tới khái niệm giá trị. Giải thích một cách đơn giản, giá trị là một cái gì đó mà người ta cảm thấy quan trọng, có ích. Cụm từ "quan trọng" và "có ích lợi” là rất đáng lưu tâm trong xây dựng VHDN. Bởi lẽ lãnh đạo công ty sẽ rất khó xây dựng VHDN, nếu không bảo vệ ích lợi mà VHDN đem lại. Nhân viên cần được giáo dục nhận thức rằng việc đeo thẻ nhân viên, mặc đồng phục là thể hiện sự tự hào là thành viên của công ty, và có ích cho công việc của họ chứ không phải họ mang những thứ đó đề làm quảng cáo.

Nếu không giảng giải được cặn kẽ hệ thống các giá trị VHDN có ích lợi gì với nội bộ tổ chức, tất yếu mọi hình thức triển khai chỉ là phong trào. Một câu hỏi được đặt ra rằng, vậy những giá trị nào là hợp lý và giá trị nào là không hợp lý. Điều này tùy thuộc rất nhiều vào từng tổ chức riêng biệt, nhưng tựu chung lại, có một số giá trị được đề cao trong nội bộ tổ chức ở Việt Nam đó là:

- Sự thành thực (thể hiện là nói thật, không gian dối, cam kết thực hiện những gì mình hứa hẹn và đảm bảo đúng những gì mình sẽ thực hiện)

- Sự tự giác (thể hiện ở mức độ sẵn sàng với công việc, không ngại khó khăn, làm việc hết mình vì lợi ích của tổ chức)

- Sự khôn khéo (biết nói những gì cần nói, hỏi những điều cần hỏi, tranh luận những điều đáng tranh luận và sắp xếp những gì hợp lý nhất)

Ngoài ra còn một số giá trị khác được đề cập tới như sự tự tin, sáng tạo ... Những giá trị này sẽ là nền tảng định hướng cho VHDN.

\section{Lọii ích văn hóa doanh nghiệp mang lại}

\section{Lơi ích của văn hóa doanh nghiệp giúp doanh nghiệp và mỗi cá nhân phát} triển

VHDN là yếu tố chi phối hầu hết mọi kết quả của doanh nghiệp. Nếu doanh nghiệp không có văn hóa doanh nghiệp rõ ràng thì giống như một con người không có định hướng mục tiêu cuộc đời và không biết đi về đâu.

Các công ty phát triển lớn mạnh đều có nền VHDN vững chắc, tuổi đời của một doanh nghiệp có nền văn hóa vững chắc lớn hơn rất nhiều lần tuổi đời của người lãnh đạo doanh nghiệp đó. Với mỗi cá nhân hiện đang là thành viên của một doanh nghiệp bât kì, hãy thực hiện đúng văn hóa của doanh nghiệp mà bạn đang công tác, bởi những điều tưởng chừng như đơn giản và nhỏ nhoi ấy lại có ảnh hưởng lớn đến cuộc sống của bạn theo hướng tích cực hoặc tiêu cực tùy vào thái độ thực hiện của bạn.

\section{Tạo động lụ̣c làm việc}

VHDN giúp nhân viên thấy rõ mục tiêu, định hướng và bản chất công việc mình làm. VHDN còn tạo ra các mối quan hệ tốt đẹp giữa các nhân viên và một môi trường làm việc thoải mái, lành mạnh. VHDN phù hợp giúp nhân viên có cảm giác mình làm công việc có ý nghĩa hãnh diện vì là một thành viên của doanh nghiệp. Điều này càng có ý nghĩa khi tình trạng "chảy máu chất xám” đang phổ 
biến. Lương và thu nhập chỉ là một phần của động lực làm việc. Khi thu nhập đạt đến một mức nào đó, người ta sã̃n sàng đánh đổi chọn mức thu nhập thấp hơn để được làm việc ở một môi trường hoà đồng, thoải mái, được đồng nghiệp tôn trọng.

\section{2. Điều phối và kiểm soát}

VHDN điều phối và kiểm soát hành vi các nhân bằng các câu chuyện, truyền thuyết; các chuẩn mực, thủ tục, quy trình, quy tắc... Khi phải ra một quyết định phức tạp, văn hoá doanh nghiệp giúp ta thu hẹp phạm vi các lựa chọn phải xem xét.

\section{Giảm xung đột}

VHDN là keo gắn kết các thành viên của doanh nghiệp. Nó giúp các thành viên thống nhất về cách hiểu vấn đề, đánh giá, lựa chọn và định hướng hành động. Khi ta phải đối mặt với xu hướng xung đột lẫn nhau thì văn hoá chính là yếu tố giúp mọi người hoà nhập và thống nhất.

\section{Lọi thế cạnh tranh}

Tổng hợp các yếu tố gắn kết, điều phối, kiểm soát, tạo động lực... làm tăng hiệu quả hoạt động và tạo sự khác biệt trên thị trường. Hiệu quả và sự khác biệt sẽ giúp doanh nghiệp cạnh tranh tốt trền thị trường.

\section{1. Đặc trưng của văn hóa doanh nghiệp}

VHDN có ba nét đặc trưng, đó là:

- VHDN mang “tính nhân sinh", tức là gắn với con người. Tập hợp một nhóm người cùng làm việc với nhau trong tổ chức sẽ hình thành nên những thói quen, đặc trưng của đơn vị đó. Do đó, VHDN có thể hình thành một cách "tự phát" hay "tự giác". Theo thời gian, những thói quen này sẽ dần càng rõ ràng hơn và hình thành ra "cá tính" của đơn vị. Nên, một doanh nghiệp, dù muốn hay không, đều sẽ dần hình thành văn hoá của tổ chức mình. VHDN khi hình thành một cách tự phát có thể phù hợp với mong muốn và mục tiêu phát triển của tổ chức hoặc không. Chủ động tạo ra những giá trị văn hoá mong muốn là điều cần thiết nếu doanh nghiệp muốn văn hóa thực sự phục vụ cho định hướng phát triển chung, góp phần tạo nền sức mạnh cạnh tranh của mình.

- VHDN có "tính giá trị”. Không có VHDN “tốt” và "xấu” (cũng như cá tính, không có cá tính tốt và cá tính xấu), chỉ có văn hoá phù hợp hay không phù hợp (so với định hướng phát triển của doanh nghiệp). Giá trị là kết quả thẩm định của chủ thể đối với đối tượng theo một hoặc một số thang độ nhất định; và những nhận định này được thể hiện ra thành "đúng-sai", "tốt-xấu", "đẹp-xấu"..., nhưng hàm ý của "sai" của "xấu", về bản chất, chỉ là "không phù hợp". Giá trị cũng là khái niệm có tính tương đối, phụ thuộc vào chủ thể, không gian và thời gian. Trong thực tế, người ta hay áp đặt giá trị của mình, của tổ chức mình cho người khác, đơn vị khác, nên dễ có những nhận định "đúng-sai" về văn hoá của một doanh nghiệp nào đó.

- VHDN có “tính ổn định”. Cũng như cá tính của mỗi con người, văn hoá doanh nghiệp khi đã được định hình thì "khó thay đổi”. Qua thời gian, các hoạt động khác nhau của các thành viên doanh nghiệp sẽ giúp các niềm tin, giá trị được tích lũy và tạo thành văn hoá. Sự tích lũy các giá trị tạo nên tính ổn định của văn hoá.

\section{Thực thi văn hoá trong Trung tâm Điều độ HTĐ miền Bắc 2.1. Cam kết với đảng, chính phủ với chính quyền và nhân dân}


Với phương châm học tập và làm theo tấm gương đạo đức của Chủ tịch Hồ Chí Minh. EVNNRLDC cam kết hoàn thành tốt nhiệm vụ Đảng và Chính phủ giao phó, đảm bảo cung cấp điện chất lượng ổn định, an toàn cho sự phát triển kinh tế, chính trị, văn hoá xã hội của các tỉnh trền địa bàn Trung tâm quản lý. Mỗi cán bộ, công nhân viên của EVNNRLDC ý thức rõ vai trò, trọng trách của Trung tâm đối với an ninh năng lượng Quốc gia, với sự phát triển kinh tế xã hội, cam kết tận tâm và trách nhiệm, sáng tạo và hiệu quả khi thực hiện những chủ trương, chính sách của Đảng và Chính phủ với phương châm "Trái tim người thợ điện còn đập thì dòng điện không bao giờ tắt".

\subsection{Cam kết với người lao động}

\section{"Ngưòi lao động là tài sản quý giá nhất"}

- Luôn đảm bảo ổn định việc làm và đời sống của người lao động. Mọi cán bộ, công nhân viên EVNNRLDC sẽ luôn được quan tâm, chăm sóc đầy đủ các quyền lợi về vật chất và tinh thần theo quy định của Pháp luật và của Ngành.

- Đảm bảo xây dựng các chế độ đãi ngộ, công bằng, minh bạch.

- Luôn khuyến khích, tạo điều kiện cho người lao động rèn luyện, trau dồi kiến thức, kỹ năng để phát triển. Khuyến khích đề cao các ý tưởng sáng tạo và tạo điều kiện tối ta để các ý tưởng sáng tạo được áp dụng vào thực tiễn.

- Mọi Cán bộ, công nhân viên phải được đánh giá đúng và được lắng nghe; thành tích luôn phải được đánh giá chính xác, kịp thời, công bằng và công khai. Người có khuyết điểm phải chịu hình thức kỷ luật theo mức độ thích hợp.

\section{3. Úng xử nội bộ}

\subsubsection{Văn hoá trong giao tiếp}

- Trang phục gọn gàng, lịch sự, đeo thẻ tên trong thời gian làm việc và trong giao dịch công tác theo quy định trong toàn Trung tâm.

- Trang phục gọn gàng, lịch sự: Theo quy định trong toàn Trung tâm, đeo thẻ tên trong thời gian làm việc.

- Tác phong khi giao tiếp, ứng xử phải văn minh, lịch sự, luôn đảm bảo phù hợp với thứ bậc (tuổi tác, cấp bậc, chức vụ), văn hoá từng vùng, miền.

- Thực hiện nếp sống văn minh, thanh lịch, văn hoá trong khi tham gia giao thông, tuyệt đối chấp hành luật an toàn giao thông luôn đảm bảo an toàn tuyệt đối.

- Luôn cư xử tế nhị xuất phát theo nguyên tắc con Người là chủ thể của toàn xã hội, thái độ lễ phép, cầu thị, tác phong lịch sự, khiêm nhường, giản dị.

\subsubsection{Văn hoá trong giới thiệu và tự giói thiệu}

- Giới thiệu người trong cơ quan trước với đối tác. Ủu tiên giới thiệu theo chức vụ, tuổi tác từ cao đến thấp.

- Giới thiệu người có địa vị thấp cho người có địa vị cao (giới thiệu tên kèm theo chức vụ đảm nhiệm).

- Giới thiệu với đối tác: ngắn gọn, dễ hiểu.

- Khi tự giới thiệu: thái độ lịch sự, khiêm nhường.

\subsubsection{Văn hoá trong úng xử với đồng nghiệp}


- Trong quan hệ với bạn bè, đồng nghiệp: Có đạo đức trong sáng, trung thực và lành mạnh; Có tác phong nhiệt tình, vui vẻ, và giản dị. Luôn có thái độ khiêm tốn, tôn trọng đồng nghiệp, kính trên, nhường dưới tạo nên bầu không khí phấn khởi thi đua sôi nổi trong cơ quan.

- Có tinh thần đoàn kết, tương thân, tương ái sã̃n sàng giúp đỡ lẫn nhau trong công việc cũng như trong sinh hoạt thường ngày để cùng tiến bộ.

- Luôn có thái độ vui vẻ, hòa nhã với mọi người, tôn trọng và học hỏi kinh nghiệm của những người đi trước đồng thời trao đổi, góp ý và tạo mọi điều kiện để đồng nghiệp mình ngày càng hoàn thiện và phát triển.

\subsubsection{Văn hoá giao tiếp qua điện thoại}

- Đặt chuông điện thoại vừa phải để không làm ảnh hưởng đến người khác. Không để điện thoại kêu quá lâu. Khi nhận hoặc gọi điện thoại cần chào hỏi, xưng danh lịch sự, nói ngắn gọn, rõ ràng, giọng truyền cảm để người nghe hiểu được nội dung cuộc đàm thoại.

- Không cắt ngang giữa chừng, không tranh cãi qua điện thoại, luôn lắng nghe trước, luôn giữ thái độ bình tĩnh, hoà nhã. Nếu không thể giải quyết qua điện thoại nên hẹn gặp trực tiếp để trao đổi.

- Khi cuộc gọi kết thúc: Cần chào hoặc cảm ơn và đặt máy nhẹ nhàng.

\subsubsection{Văn hoá trong công việc}

- Mọi hành động, mọi lời nói, mọi việc làm phải được thực hiện theo nguyên tắc tuân thủ quy định của Pháp luật, của EVN và EVNNRLDC.

- Luôn đề cao vai trò, trách nhiệm cá nhân, không trốn tránh, đối phó, đùn đẩy trách nhiệm. Thực hiện tự phê bình và phê bình nghiêm túc, chân thành, thẳng thắn, có thái độ cầu thị khắc phục mọi khó khăn để thực hiện hoàn thành tốt mọi công việc được giao.

- Toàn tâm, toàn ý trong công việc, thực hiện hết trách nhiệm được giao, đảm bảo hoàn thành công việc một cách nhanh chóng, chính xác và hiệu quả nhất.

- Lãnh đạo cấp trên luôn lắng nghe và chia sẻ với cấp dưới, ngược lại cấp dưới luôn phục tùng sự điều hành của cấp trên khi đã được thống nhất và quyết định. Chấp hành nghiêm chỉnh Quy chế dân chủ ở cơ sở, luôn hợp tác, chia sẻ kiến thức, thông tin để giải quyết công việc đạt chất lượng và hiệu quả cao nhất, vì lợi ích chung của Trung tâm và vì sự phát triển chung của đất nước.

- Không lạm dụng, lợi dụng quyền lực, chức vụ, hay nhiệm vụ được giao để thực hiện các hành vi vi phạm đạo đức nghề nghiệp, vi phạm các nội quy, quy định của cơ quan.

\subsubsection{Văn hoá nơi làm việc}

- Cán bộ, công nhân viên EVNNRLDC cam kết: Luôn chấp hành tốt Nội quy và Quy chế của cơ quan hoặc nơi làm việc, có thái độ vui vẻ, niềm nở, nhiệt tình đối với khách hàng, đối tác, nhà cung cấp và đồng nghiệp. Thực hiện nghiêm trang nơi công sở và nghiêm túc khi làm việc.

- Có ý thức giữ gìn cảnh quan, môi trường sạch sẽ, gọn gàng, đảm bảo an toàn lao động và Quy định về phòng chống cháy, nổ.

- Luôn giữ gìn trật tự nơi làm việc tại các công sở. Khi ra khỏi phòng hoặc nghỉ làm việc 
phải tắt các thiết bị dùng điện nếu thấy không cần thiết, khi ra về phải tắt nguồn điện trong phạm vi của mình để đảm bảo tuyệt đối an toàn.

\subsubsection{Văn hoá khi làm việc}

- Luôn đảm bảo đúng thời gian làm việc và công tác, có tác phong nhanh nhẹn, lịch thiệp, thái độ nghiêm túc, nhiệt tình và trách nhiệm khi thực thi nhiệm vụ.

- Không biểu lộ vấn đề cá nhân khi làm việc.

- Luôn phát huy sáng kiến cải tiến kỹ thuật, có tinh thần sáng tạo và kịp thời đúc rút kinh nghiệm trong công việc, biết chia sẻ, khắc phục khó khăn để hoàn thành tốt công việc được giao.

- Hệ thống các văn bản, tài liệu của EVNNRLDC phải được soạn thảo và ban hành đúng quy trình và thể thức, phù hợp với đường lối, chủ trương của Đảng, chính sách và pháp luật Nhà nước, tuân thủ những nội quy, quy định của ngành và của EVNNRLDC.

- Mỗi cán bộ, công nhân viên EVNNRLDC đều phải nêu cao tinh thần trách nhiệm trong việc bảo vệ, giữ gìn, quản lý và sử dụng các tài sản của Trang tâm cũng như tài sản Nhà nước. Khai thác và sử dụng đúng mục đích, có hiệu quả các tài sản đó chống tham ô, lãng phí.

- EVNNRLDC khuyến khích cán bộ, công nhân viên phấn đấu học tập và trau dồi kiến thức để nâng cao trình độ chuyên môn, nghiệp vụ để phục vụ cho nhiệm vụ chính trị và nâng cao hình ảnh tốt đẹp của Trung tâm trong và ngoài nước.

\subsubsection{Văn hoá hội họp}

- Luôn có mặt trước khi cuộc họp bắt đầu. Hiểu rõ nội dung cuộc họp được tham dự và chuẩn bị đầy đủ tài liệu liên quan đến cuộc họp, các ý kiến phát biểu, tham luận phải được chuẩn bị kỹ càng, cô đọng, dể hiểu.

- Nếu không thể tham dự vì lý do chính đáng phải báo cáo với Ban tổ chức trước khi cuộc họp được bắt đầu.

- Ngồi đúng vị trí đã được sắp xếp, có thái độ văn minh, lịch sự tôn trọng mọi người xung quanh, tuân thủ nội quy, quy chế làm việc và sự điều hành của ban tổ chức cũng như người chủ trì cuộc họp.

- Điện thoại luôn đặt ở chế độ rung, hạn chế nghe điện thoại trong giờ họp, nếu cần, phải cần ra khỏi phòng để đảm bảo không làm ảnh hưởng đến cuộc họp.

- Luôn lắng nghe ý kiến của người khác với tinh thần xây dựng, trường hợp muốn trình bày ý kiến cần đăng ký trước với ban tổ chức hoặc xin phép chủ tọa cuộc họp, tuyệt đối không chen ngang hay ngắt lời người khác.

- Không làm các việc riêng khác trong giờ họp.

Sau một thời gian thực thi VHDN, hình ảnh một Trung tâm Điều độ HTĐ miền Bắc nói riêng và Tập đoàn điện lực Việt Nam nói chung uy tín, thân thiện, tận tâm đang dần được hình thành trong mắt khách hàng sử dụng điện, các đối tác và cộng đồng xã hội. Phát huy những thành quả đó, $\mathrm{CBCNV}$ và người lao động tại Trung tâm đã và đang không ngừng nỗ lực, hoàn thiện bản thân, chung tay xây dựng một EVN lớn mạnh với bản sắc văn hóa riêng, tạo nên giá trị bền vững của một Tập đoàn kinh tế nhà nước hàng đầu trong hội nhập kinh tế quốc tế...

\section{TÀI LIỆU THAM KHẢO}




\section{Tài liệu tham khảo:}

[1] Trung tâm Điều độ Hệ thống điện miền Bắc. (2019). EVN NRLDC XÂY DỰNG VĂN HÓA DOANH NGHIẸ̃P (VHDN). https://www.nrldc.evn.vn/newsg/19/9919/XAY-DUNG-VANHOA-DOANH-NGHIEP-VHDN-YEU-TO-QUYET-DINH-SU-TRUONG-TON-CUA-DOANHNGHIEP/default.aspx

[2] Vương Quân Hoàng. (2007). Văn minh làm giàu \& Nguồn gốc của cải. Nxb Chính trị quốc gia, Hà Nội.

[3] Tập đoàn điện lực Việt Nam. (2018). Tài liệu văn hóa doanh nghiệp. EVN. 